\title{
Jean-Paul Goujon, Virtus durissima coquit ou les avatars d'une autruche baudelairienne
}

\section{Maria Emanuela Raffi}

\section{(2) OpenEdition}

1 Journals

\section{Edizione digitale}

URL: http://journals.openedition.org/studifrancesi/2233

DOI: 10.4000/studifrancesi.2233

ISSN: 2421-5856

\section{Editore}

Rosenberg \& Sellier

\section{Edizione cartacea}

Data di pubblicazione: 1 aprile 2014

Paginazione: 174

ISSN: 0039-2944

\section{Notizia bibliografica digitale}

Maria Emanuela Raffi, « Jean-Paul Goujon, Virtus durissima coquit ou les avatars d'une autruche baudelairienne ", Studi Francesi [Online], 172 (LVIII | I) | 2014, online dal 01 avril 2014, consultato il 18 septembre 2020. URL : http://journals.openedition.org/studifrancesi/2233 ; DOI : https://doi.org/ 10.4000/studifrancesi.2233

Questo documento è stato generato automaticamente il 18 settembre 2020.

\section{(c)}

Studi Francesi è distribuita con Licenza Creative Commons Attribuzione - Non commerciale - Non opere derivate 4.0 Internazionale. 


\title{
Jean-Paul Goujon, Virtus durissima coquit ou les avatars d'une autruche baudelairienne
}

\author{
Maria Emanuela Raffi
}

\section{NOTIZIA}

JEAN-PAUL GOUJON, Virtus durissima coquit ou les avatars d'une autruche baudelairienne, «Histoires littéraires», XIII, 52, octobre-décembre 2012, pp. 41-52.

1 Riflettendo sul motto latino inciso da Rops nell'edizione originale delle Épaves di Baudelaire - Virtus durissima coquit -, sull'emblema che lo contiene e sulle spiegazioni fornite da Claude Pichois nella sua edizione delle CEuvres complètes del 1975, Goujon approfondisce l'origine del singolare motivo dello struzzo che inghiotte un ferro di cavallo accompagnato dall'iscrizione latina che Pichois riconosce nel Symbolorum et Emblematum di Joachim Camerarius del 1596. In particolare l'A. scopre nel Dialogue des devises d'armes et d'amours di Paolo Govio (1559) che quest'ultimo aveva creato per Girolamo Mattei Romano proprio l'emblema di uno struzzo che inghiotte un chiodo per significare «qu'un vaillant cœur ha pouvoir de digerer avec le temps toute griefve injure», con il motto Spiritus durissima coquit. Il passaggio da Spiritus a Virtus, indicato da Pichois in relazione al testo di Camerarius (Spiritus), viene segnalato da Goujon come acquisito già in una raccolta di simboli del $1699 \mathrm{e}$ in altre raccolte successive di emblemi. L'A. si pone quindi una domanda conclusiva: Rops e l'editore Poulet-Malassis si sono forse ispirati ad un testo più tardo di quello di Camerarius, dato che a partire dal XVII secolo molte raccolte di emblemi riportano già l'immagine dello struzzo che inghiotte un ferro di cavallo accompagnata dal motto Virtus durissima coquit? 